TAO, Vol. 11, No. 3, 609-630, September 2000

\title{
An Interpretation of the 1999 Chi-Chi Earthquake in Taiwan Based on the Thin-Skinned Thrust Model
}

\author{
Chien-Ying Wang ${ }^{1,}{ }^{*}$, Chien-Hsin Chang $^{1}$ and Horng-Yuen Yen ${ }^{1}$
}

(Manuscript received 15 March 2000, in final form 29 May 2000)

\begin{abstract}
The 1999 Chi-Chi earthquake $\left(M_{L}=7.3\right)$ which occurred in central Taiwan marks the island's largest inland seismic event of the twentieth century. The Chi-Chi earthquake had three notable characteristics: 1) its source depth was very shallow $(8 \mathrm{~km})$, with aftershocks distributed in a semi-circular belt surrounding the Peikang basement high; 2) it triggered a $90 \mathrm{~km}$ long, north-south trending, active fault (the Chelungpu fault), mostly of the thrust type. Its hanging wall side suffered much larger distortions than the foot wall side; and 3) the fault trace bent toward the northeast at its northern tip $50 \mathrm{~km}$ away from the source, where the largest surface rupture occurred $(9.8 \mathrm{~m})$.

We suggest that the thin-skinned thrust model would be the most suitable to explain the behavior of the Chi-Chi earthquake. The overall decollement surface might not be too deep $(20 \mathrm{~km}$ ?), which would redistribute the tectonic pressure to a weak near-surface layer, this could be the Chinshui Shale $(10 \mathrm{~km}$ ?) which activated the brittle layer-coupled fault even before the accumulation of earthquake stress in the near area was 'mature' or 'adequate'. By using the aftershock data and other observations, we attempt to reconcile the different aspects of the Chi-Chi earthquake based on the thin-skinned model. Many inferences emerge as remarkably reasonable, that match the observations quite well. However, a deep seismic reflection study or deep well drilling is definitely required to better evaluate the model.
\end{abstract}

(Key words: Chi-Chi earthquake, Thin-skinned, Taiwan tectonics)

\section{INTRODUCTION}

In the early morning (01:47 local time) of September 21,1999 , an $M_{L}=7.3\left(M_{W}=7.6\right)$

\footnotetext{
${ }^{1}$ Institute of Geophysics, National Central University, Chung-Li, Taiwan , ROC

${ }^{\star}$ Corresponding author address: Prof. Chien-Ying Wang, Institute of Geophysics, National Central University, Chung-Li, 320 Taiwan, ROC; E-mail: wang@sss.gep.ncu.edu.tw
} 
earthquake struck central Taiwan near the small town of Chi-Chi. This was the largest earthquake on Taiwan island in the $20^{\text {th }}$ century, which caused 2470 fatalities, 11,305 injuries, 53,551 buildings totally collapsed, and 53,633 half collapsed. The total capital lost was estimated to be US $\$: 11.8$ billion (4\% of Taiwan's GNP).

The Chi-Chi earthquake had three particular and interesting characteristics:

(1)The source depth was very shallow $(8 \mathrm{~km})$ with the focal mechanism being a pure reverse fault dipping shallowly to the east. The aftershocks were distributed along a semi-circular belt (crescent shape) fringing the epicenter as well as the Peikang basement high.

(2)It triggered an active fault (the Chelungpu fault), which was $90 \mathrm{~km}$ long, north-south trending, and was mostly of the thrust type. The hanging wall side had much larger displacement and greater damage than the foot wall side, which made the fault trace like a dividing line for ground deformations. However, the distribution of aftershocks did not seem closely related to the fault.

(3)The fault trace bent toward the northeast at its northern tip (50 km away from the center) where the largest surface rupture was measured, $9.8 \mathrm{~m}$ horizontally and $5.6 \mathrm{~m}$ vertically. The source fault-slip during the occurrence of the earthquake also appeared to be the largest ( 7 to $10 \mathrm{~m}$ ) under this region.

Dense landslides were induced, the number being as high as 2,365 distributed over an area of 14,300 hectares. The Tsaoling mountain, for example, had a 690 ha downfall with the mass rushing across the stream at its foot to the other side. An earthquake-induced dam was thus formed. The surface dislocations were spread over a wide mountain region mostly on the eastern side of the epicenter.

The theory of thin-skinned thrust faulting is apparently the most suitable to explain the strange behavior of the Chi-Chi earthquake. This thin-skinned model has long been used to interpret many structural features of Taiwan (Suppe 1980a,b), especially the imbricated stuctures in the western foothill area (Suppe 1984). By observing a particular lower Miocene layer, the Wuchihshan formation, at similar depths in different wells in northwestern Taiwan, many geologists agree that there exists a decollement which may have detached the overlying younger structures, crumpled them up to form the fold and fault belt, but left the underlying structures untouched (Elishewitz 1963; Biq 1972). Although some recent data tend to indicate that there are thick roots under the Central Range and the Coastal Range (Wu et al. 1997; Wu and Rau 1998; Yeh et al. 1998), the thin-skinned shear faulting theory still best explains the structures surrounding the Peikang basement high in western Taiwan.

This paper will summarize various observations of the Chi-Chi earthquake, propose some postulations, and attempt to connect these with the thin-skinned model. Many puzzling factors about the Chi-Chi earthquake will become easier to understand if a less resistant, low-angle, shear fault is accepted as the controlling factor for this earthquake.

\section{TECTONIC AND GEOLOGIC SETTINGS}

Taiwan is located in a complex, tectonically active region (Fig. 1). The island developed as the result of a late Cenozonic oblique collision between the Philippine Sea plate and the 


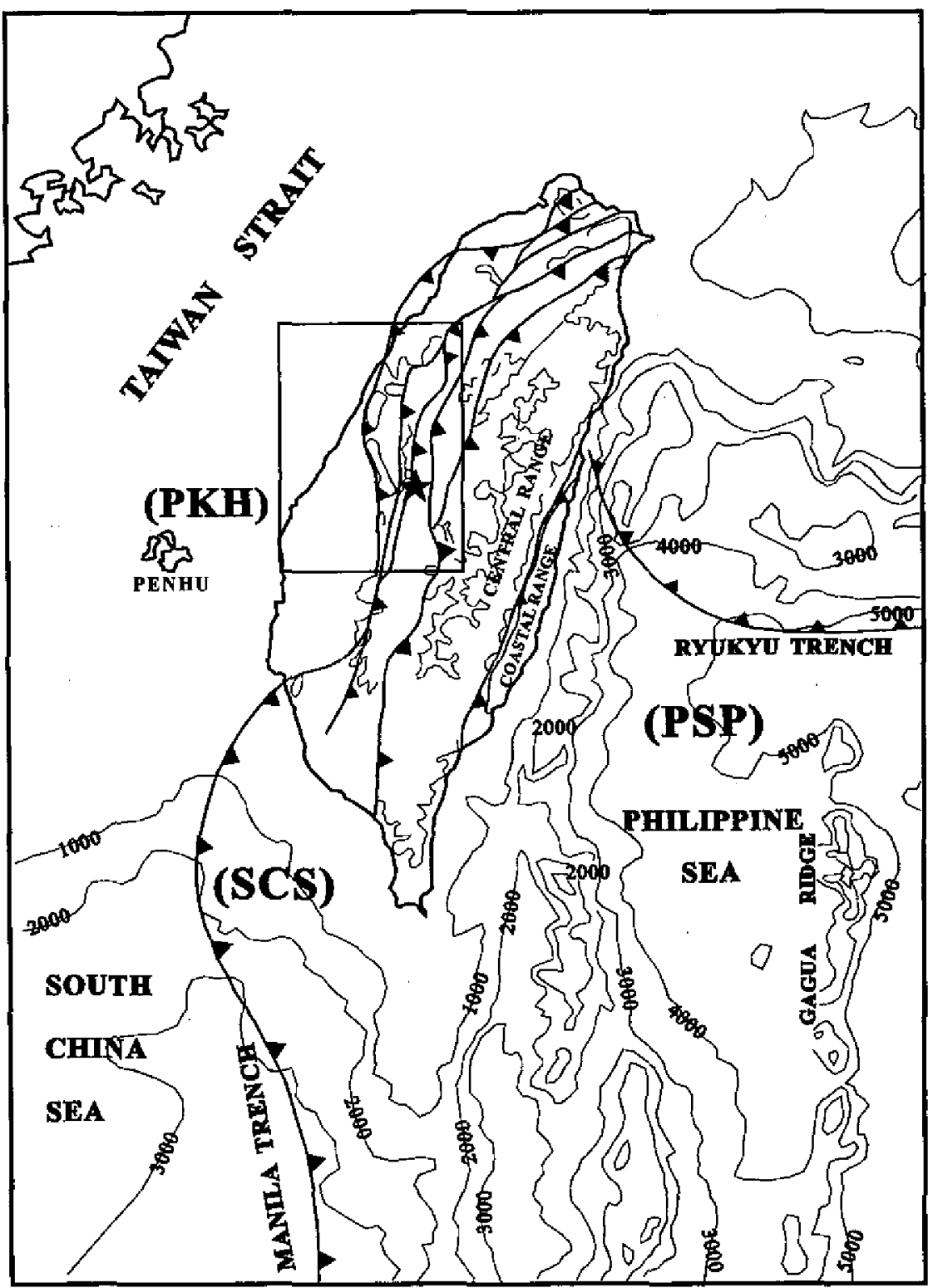

Fig. 1. Present-day tectonic setting of Taiwan (modified from Suppe, 1980a). Three tectonic systems are involved: 1) the Philippine Sea Plate (PSP) in the east, 2) the South China Sea (SCS, part of Eurasian plate but oceanic) in the southwest, and 3) the PeiKang basement High (PKH, part of Eurasian plate but continental) in the west (Taiwan Strait). The deformation front runs along the most western thrust line. The Chi-Chi earthquake is denoted by a start located just at the center of the island. The square around the epicenter shows the area of Fig. 2. 
Eurasian plate (Suppe 1984; Barrier 1986; Ho 1986; Teng 1990; Lu and Hsu 1992; Liu et al. 1997; Wu et al. 1997). This ongoing collision caused numerous earthquakes to occur in its eastern and southern sides (Wang and Shin 1998, or ref. Fig. 3), and induced scattered, but occasionally large damaging earthquakes in the western side of Taiwan in close proximity to heavy populated areas. Three tectonic systems exist around Taiwan (Fig. 1): the Philippine Sea Plate (PSP) on the east, the South China Sea (SCS, part of the Eurasian plate but oceanic) on the south, and the Pei-Kang basement High (PKH, part of the Eurasian plate but continental) on the west. The most recent orogen, called the Penglai orogeny (Penglai means Gods' island), which started about 6 million years ago, is still the prevalent tectonic force acting on the island. In the Penglai orogeny, the PSP carries the mass of the Coastal Range (the island arc) heading in the northwestern direction which collides with the passive Eurasian continental margin at an oblique angle and at an annual rate of $7 \mathrm{~cm}$ (Seno 1977). This collision has built up the Central Range as the metamorphic core of Taiwan and created many thrusts and folds in the western sedimentary foothills. The PSP subducts northward along the Ryukyu trench on the eastem offshore of the island. The Ryukyu trench connects to the Japan's system trending in the northeastern direction.

The movement of the PSP has also pushed the old SCS system, which was dominant during the Miocene time ( 20 million years ago) with the subduction along the Manila trench toward the east, to retreat toward the west (Hsu and Sibuet 1995). This interaction now controls the tectonic activity on the southern half of the island. The Manila trench connects to the Philippine's system trending in the southern direction. Since the early Tertiary time (60 million years ago), an extension system proceeding from Mainland China has created a sequence of half grabens in the Taiwan Strait (Sun 1985; Teng 1992), which even cracked the crust, erupting basaltic lava to form an islet (Penhu island, 18-8 million years ago) in the middle of the Strait. This extension system also caused development of the PKH in the middle of western Taiwan, which later acted as a barrier blocking the PSP's movement (Hu et al. 1997). Thus grossly speaking, we have three systems: the PSP, the SCS, and the PKH. Most Taiwan earthquakes occur within the framework of interactions among these three systems. The 1999 ChiChi earthquake is a typical one which represents the head-to-head collision between the PSP and the PKH in central Taiwan.

Figure 2 depicts the general geologic setting around the Chi-Chi earthquake. Most geologic features in this area trend in the south-north direction. The tectonic compression from the east has created a sequence of structural lows and highs, or faults and folds, especially in the western foothill.

Four faults are identified in Fig. 2 (from west to east): the Changhua, Chelungpu, Shuantung and Shuichangliu faults. Among these, the Chelungpu fault emerges as an important boundary separating the low level plain and basin areas from the high altitude regions of hills and mountains. Near the western coast, three gravel terraces (Pakuashan, Tatu and Houli) denote the margin of the deformation front where the tectonic force comes into contact with the $\mathrm{PKH}$ (Fig. 1). An unverified Changhua fault is placed at their western border. The varied orientation of these three small terraces, however, indicates an uneven distribution of the PKH surface underneath. The elongated Taichung basin is surrounded by these three terraces and the Chelungpu fault. This basin is full of gravels and conglomerates, which help to make the 
(a)

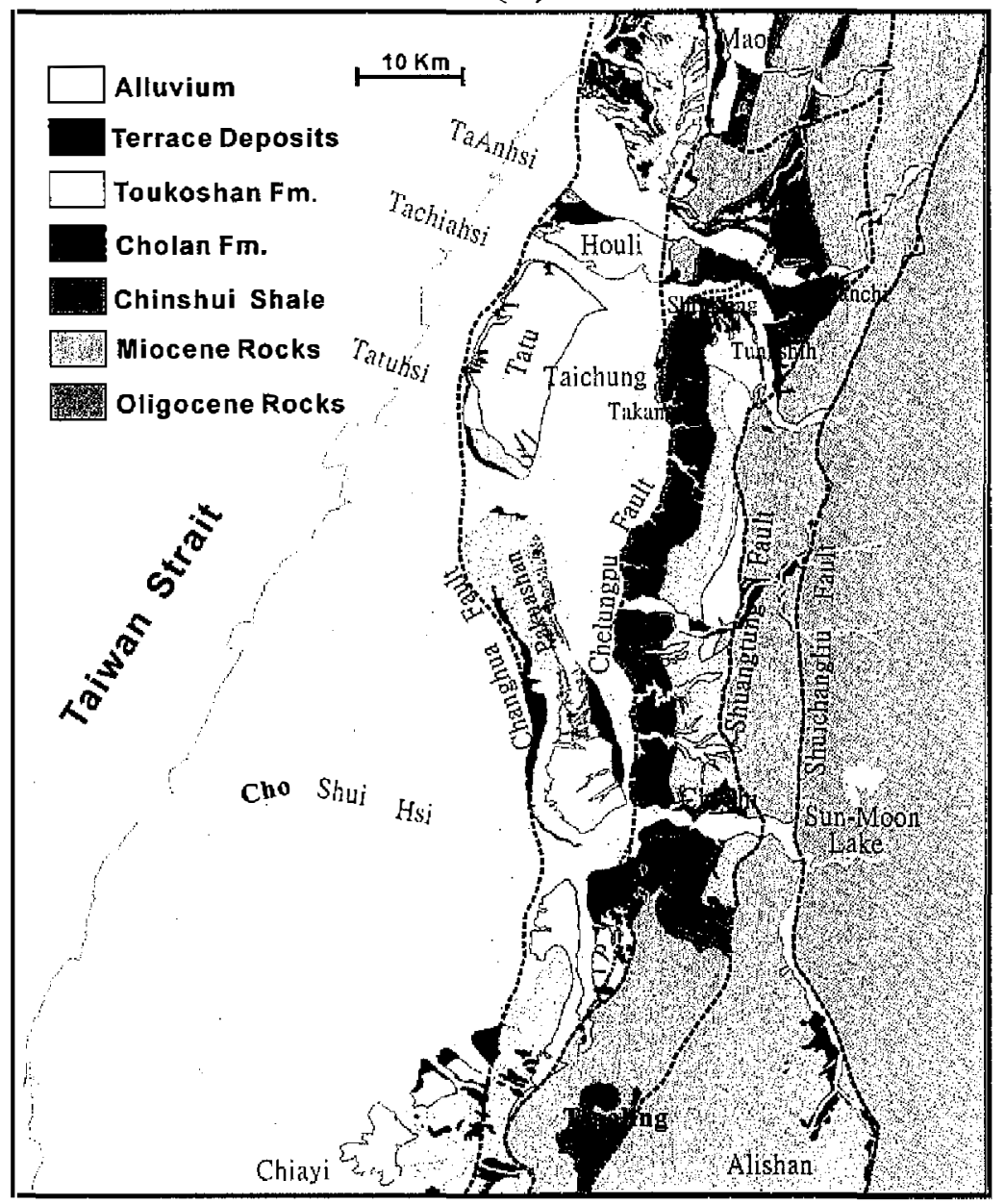

Fig. 2. (a) Geological map of central western Taiwan around the Chi-Chi earthquake area (modified from CPC). A sketched cross section of this area is given in Fig. 11. Some location names referred in the text are also given. Four faults involved in the region are (from west to east): the Changhua, Chelungpu, Shuantung and Shuichangliu faults. Three terraces: Pakuashan, Tatu and Houli are composed of Pleistocene Toukoshan formation (gravel). Between the Chelungpu and the Shuantung faults, there are Pliocene Cholan formation (sandstone and shale) and Chinshui formation (shale), and Pleistocene Toukoshan formation again. East of the Shuantung fault comes out the Miocene Kueichulin formation (massive sandstone), Nanchuang formation (sandstone, siltstone and shale), etc. To the east of the Shuichangliu fault, Oligocene Paileng formation (thick, massive quartz sandstone) is dominant. 
(b)

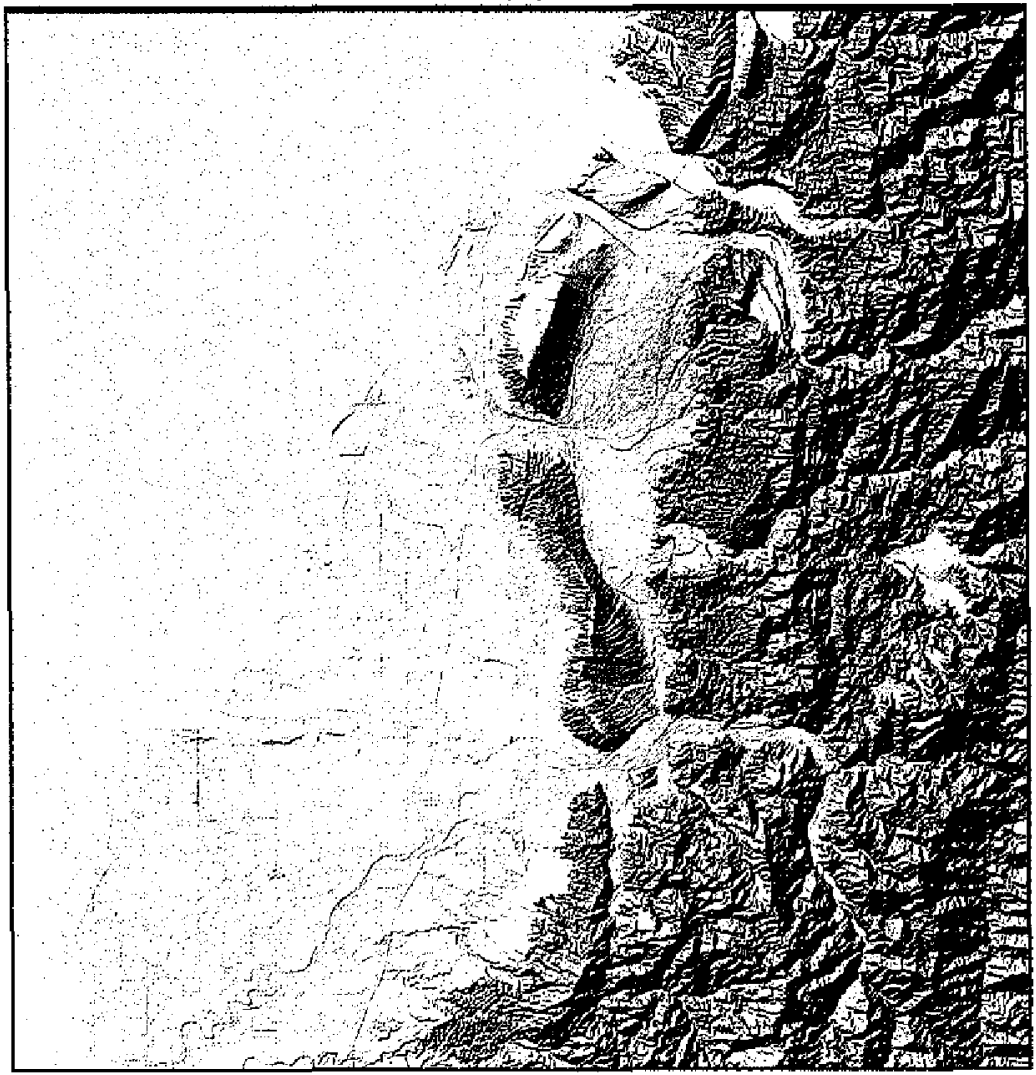

Fig. 2. (b) Shaded topographic map of the same area. Four main rivers are noted (from south to north): the Choshuihsi, Tatuchi, Tachiahsi and Ta-anhsi streams.

ground firm enough to resist earthquake shaking. The Chelungpu fault, the major actor in the Chi-Chi earthquake, is a sharp boundary that follows the edges of the hills which define the eastern border of the plain areas. Because of its obvious geomorphic shape, this fault had already been recognized as active even before the Chi-Chi earthquake (Bonilla 1977).

The northern tip of the Chelungpu fault, on the map in Fig. 2a, is directed northward across two rivers, the Tachiahsi and Ta-anhsi streams, and protrudes into the Miaoli area. During the Chi-Chi earthquake, however, the Chelungpu fault took a right turn to the east just in front of the Tachiahsi stream. This interesting bending is indicative of a distortion of the underground structures beneath these two streams. To the east of the Chelungpu fault, there are two more faults that also indicate obvious geologic boundaries between younger and older rocks, such as from Pleistocene (Toukoshan formation), Pliocene (Cholan, Chinshui formations) to Miocene (Kueichulin, Nanchuang formations, etc.), to Oligocene (Paileng forma- 
tion). Nevertheless, these two inner mountain faults might not have been involved in the action of the Chi-Chi earthquake. The mountain area here represents a highly compressed structure been shaped into an imbricated form by faulting and folding due to the enormous land shortening of about 160-200 km (Suppe 1980b). A thin-skinned thrust model has been applied to explain this large amount of land contraction, which has actually become a classic example of thrust deformation in several textbooks (e.g., Davis and Reynolds 1996)

\section{PAST SEISMICITY AND THE CHI-CHI EARTHQUAKE SEQUENCE}

Earthquake data in the Taiwan region were documented quite early, even at the beginning of the twentieth century. In the past 100 years, the seismic activity in western central Taiwan can be grouped into two different zones divided by the Choshuihsi stream, the largest river on the island (Figs. 2 and 3). In the north, the seismicity forms a linear pattern trending in the NW-SE direction, called the Tunghsiao-Puli Linear seismic zone (TPL). In this zone, an earthquake of $M_{L}=7.1$ occurred in 1935 causing 3,276 deaths. Except for this big earthquake, however, the TPL seismic zone has only had a limited number of earthquakes, and they were of low magnitudes (smaller than 4) and shallow depths (less than $20 \mathrm{~km}$ ). The seismic zone south of the Choshuihsi stream near Chia-Yi, on the contrary, has had much higher seismicity. This Chia-Yi Group seismic zone (CYG) has been full of both small and large earthquakes (Fig. 3b), and has long been the most alertly watched earthquake area on the island. This zone trends in a northeasten direction along the southern border of the PKH (Wang and Shin 1998), and has earthquakes distributed over a wider region in groups or clusters. The CYG seismic zone has been the site of many disastrous earthquakes in Taiwan, including the 1906 Meishan $\left(\mathrm{M}_{\mathrm{L}}: 7.1\right)$, the 1941 Chungpu $\left(\mathrm{M}_{\mathrm{L}}: 7.1\right)$ and the 1964 Baiho $\left(\mathrm{M}_{\mathrm{L}}: 6.4\right)$ earthquakes (Fig. 3b).

Between the TPL and CYG seismic zones, there is a seismic gap near Sun-Moon Lake (SML, Fig. 3b) which does not have significant seismicity. Before the Chi-Chi earthquake, we did not realize why there were two separated seismic zones in central Taiwan, nor why the 1935 earthquake occurred in an area that had not been very seismically active. The Chi-Chi earthquake located right around the Sun-Moon Lake seismic gap (Fig. 4); after this, we began to understand that there could actually be only one seismic zone, rather than two, surrounding the PKH. During the first four hours after the Chi-Chi earthquake, 6 aftershocks with magnitudes greater than 6.0 and 35 aftershocks with magnitudes greater than 5.0 quickly filled in the Sun-Moon Lake seismic gap (Fig. 5). They were distributed in this seismic gap rather than associated with the Chelungpu fault which had been activated by the main shock. More interestingly, the focal mechanisms for some of these big aftershocks were almost the same as that of the main shock (Fig. 5). All these facts clearly indicate that the TPL seismic zone is linked with the CYG seismic zone to form a semi-circular belt surrounding the PKH (Fig. 4). The Sun-Moon Lake seismic gap is not a seismic zone divider but rather a previously locked block contributing large earthquakes. It is certain that most of the major damaging earthquakes in Taiwan will frequently occur inside this semi-circular belt.

In the four months after the master event, thousands of aftershocks blossomed over central Taiwan, which included 15 aftershocks with magnitudes greater than 6.0, 97 greater than 
(a)

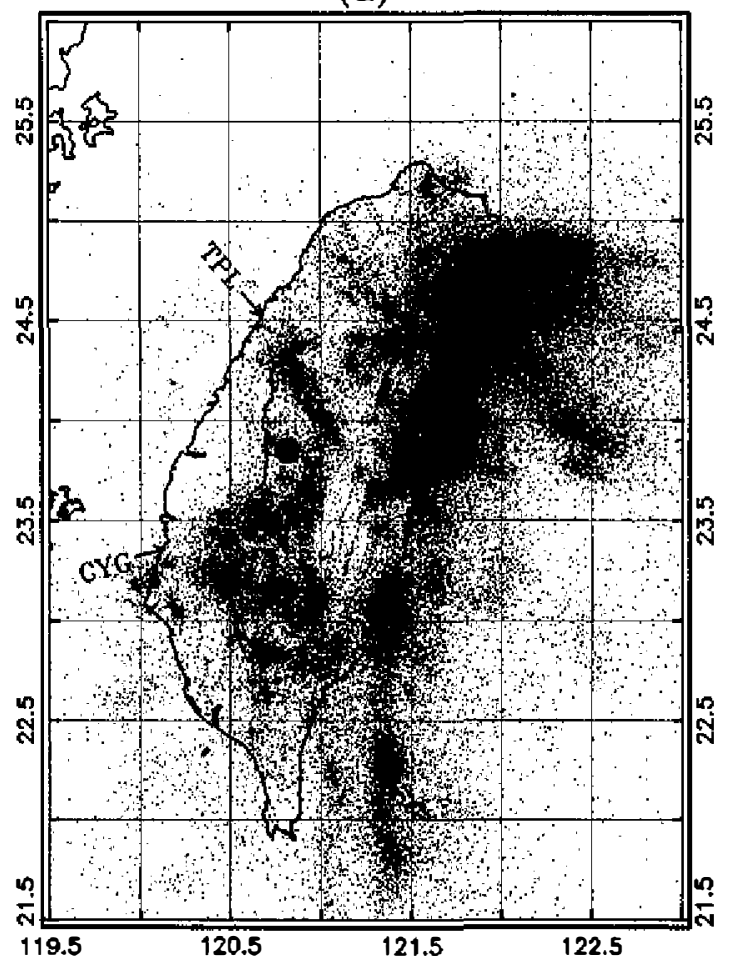

(b)

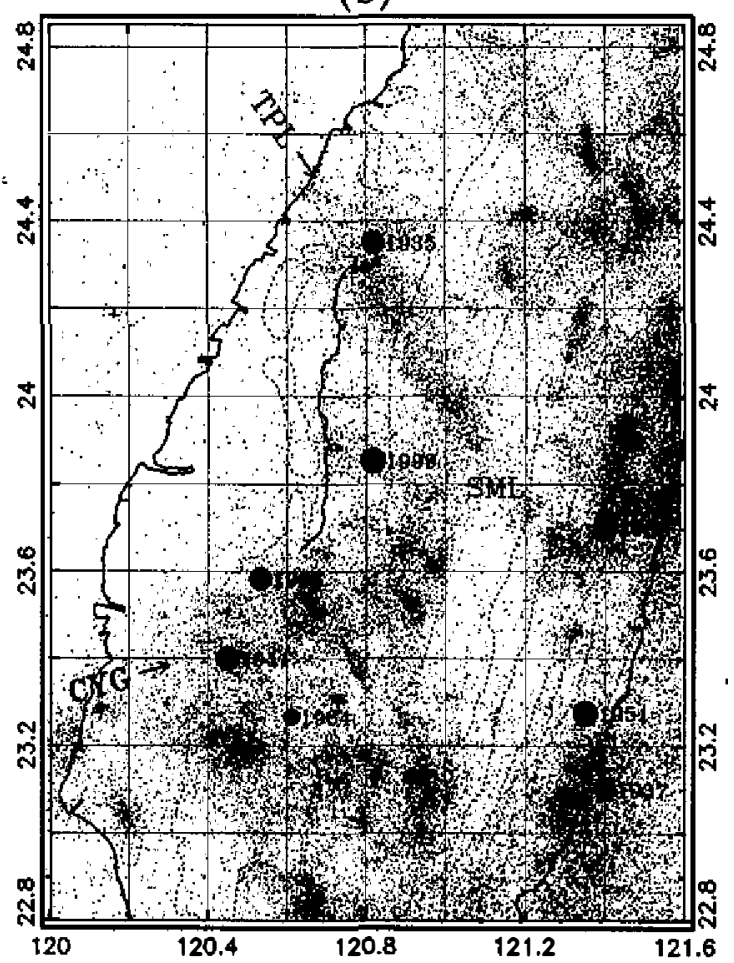

Fig. 3. (a) Taiwan seismicity over the past 100 years. The Chi-Chi earthquake (big dot) is situated near the center of Taiwan island. Two seismic zones: the Tunghsiao-Puli Linear (TPL) seismic zone and the ChiaYi Group (CYG) seismic zone embrace the epicenter. (b) Magnified portion of (a), where the Chi-Chi earthquake and some other large damaging earthquakes (M>7.0, except for the 1964 Baiho earthquake, $M=6.4$ ) are indicated by big dots. It was surprised to find that the Chi-Chi earthquake was not exactly located in any active seismic zone. Instead, it was near a seismic gap: the Sun-Moon Lake (SML) seismic gap.

5.0, 352 greater than 4.0, and 874 greater than 3.0 (Fig. 4). It is astonishing to find that most of these aftershocks were also distributed in a semi-circular belt circling the PKH exactly like those from previous seismicity data. Although there is a branch that extends from Sun-Moon Lake to Alishan (Fig. 4a), this branch still lies within the CYG seismic zone. In fact, this branch follows a geologic boundary along the Shuichangliu fault (Fig. 2). Another linear aftershock distribution appears in the eastern side of the Central Range which also has the trend to line up with some geologic boundaries. We suspect that some earthquake-related structural layers, for example, the Chinshui Shale (to be described later), may extrude to the south and that the afore-mentioned massive Tsaoling landslide (see Fig. 2a for the location) occurred 
(a)

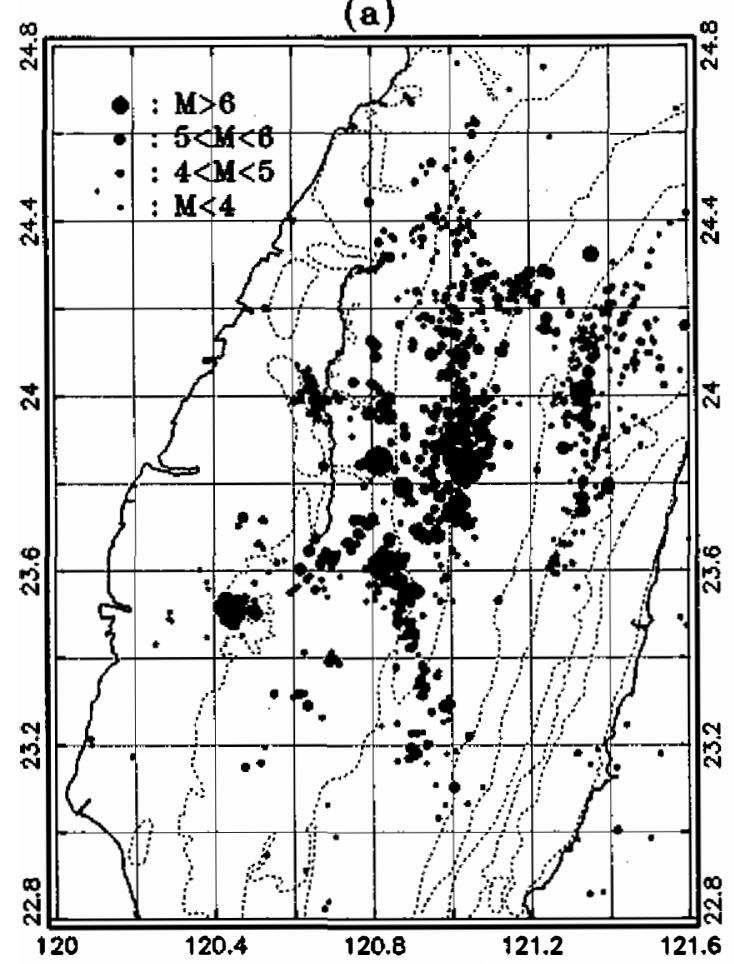

(b)

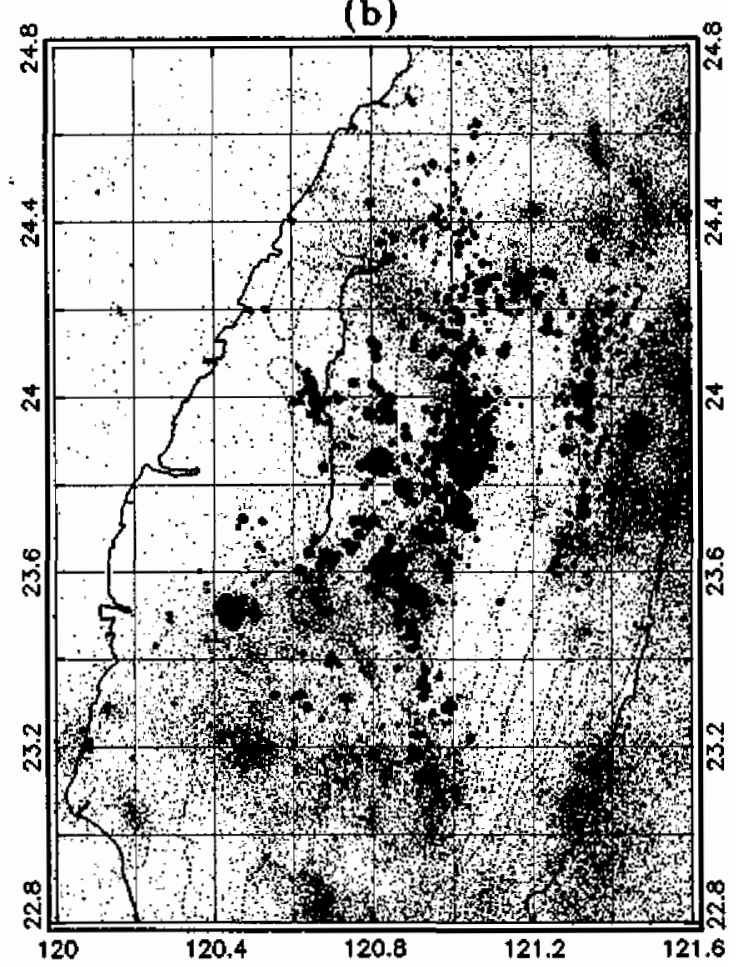

Fig. 4. (a) Aftershocks recorded in a 4-month period after the main shock with magnitudes greater than 3.0. These aftershocks were distributed in a semicircular belt (crescent shape) surrounding the PeiKang basement high. (b) Same aftershocks in (a) superimposed with the past seismicity. Some aftershocks seem to fill in the gap between the TPL and the CYG, i.e., in the Sun-Moon Lake seismic gap, whereas others were mostly located in existing seismic zones.

because the Chinshui Shale was responsible as the dip-slope lamina which elicited the mass fall. Furthermore, detailed examinations of strong motion data have revealed that three separate events were induced during the first 20 seconds of the main wavetrain (Shin 2000). Among them, two southern events were located at Tsaoling and Alishan, and the other occurred in the north near Hsinchu. These events may be referred to as side effects caused by some weak layers along the geologic boundaries. This observation will be considered in the thin-skinned thrust model to be discussed later.

Figure 4 also shows that the Chi-Chi aftershocks were distributed over an area as large as $120 \mathrm{~km}$ square (almost covering half of the island), much larger than that has occurred before on Taiwan. For example, aftershocks of the 1935 event covered a 50-km-square area and the 1946 event, 40-km-square area. Figures 6a and 6b show depth distributions of previous seis- 

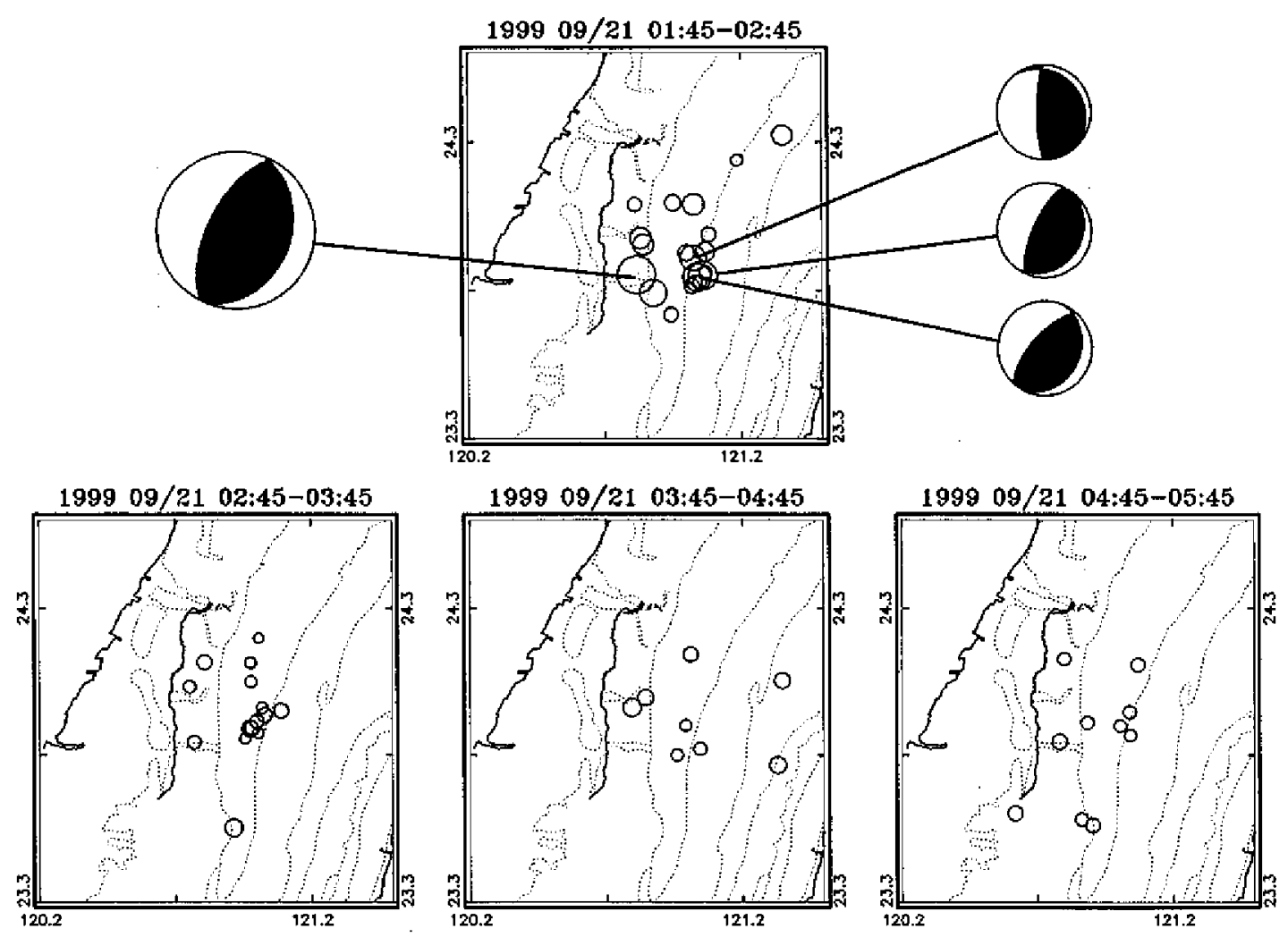

Fig. 5. Aftershocks within 4 hours after the main shock. The fault plane solutions of the main shock and three $M>6$ aftershocks are also shown to indicate their close relationships.

micity and the Chi-Chi earthquake aftershocks, respectively. Both figures indicate that the earthquakes in this area are very shallow, most being shallower than $20 \mathrm{~km}$ and many concentrated in the upper $10 \mathrm{~km}$. A zone lack of dense seismicity around $18-20 \mathrm{~km}$ is apparent (especially on Fig. 6a), which may represent a weak layer that could be a proper place for the decollement boundary (Chang et al. 2000). We also noted that some aftershocks occurred deeper than $20 \mathrm{~km}$ under the Sun-Moon Lake seismic gap, which may imply strong strain accumulations in this metamorphic rock area.

All of the aftershock features such as their high magnitudes, large number, similar focal mechanisms, wide distribution areas and shallow depths, direct one to the same point, that the main shock might not have completely discharged the accumulated distortion strain energy, which led the aftershocks carry the burden of releasing the rest. We call this the 'premature trigger' postulation for the Chi-Chi earthquake. The premature delivery of earthquake strain energy may disturb an area's balance and induce many aftershocks in the existing seismic zones. The 'premature trigger' of the main shock was closely related to the activation of the Chelungpu fault, which is also involved in the context of the thin-skinned model. 
(a)
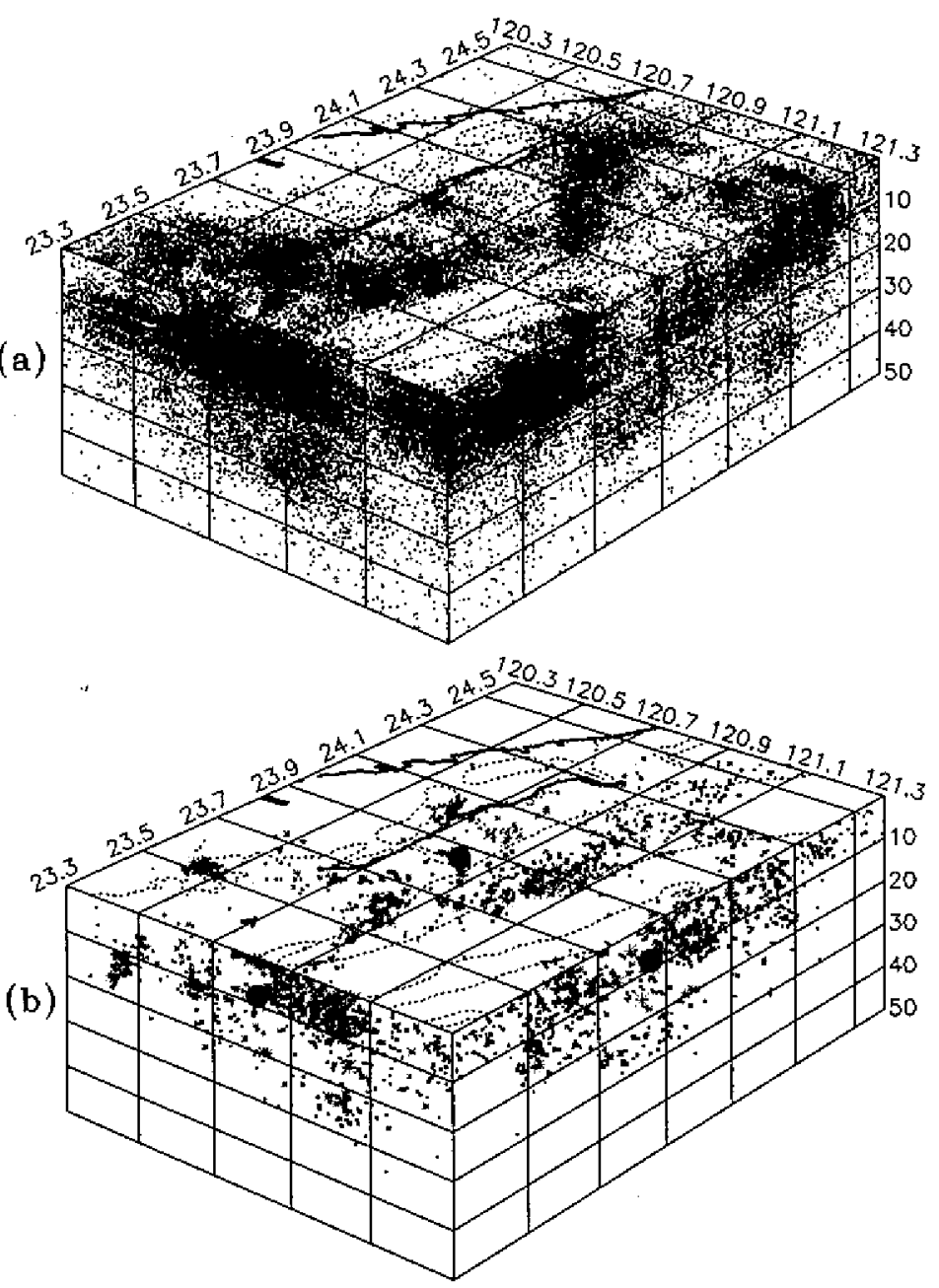

Fig. 6. Stereo maps showing (a) the depth distribution of past earthquakes, and (b) Chi-Chi aftershocks, surrounding the PKH. There seems existing a zone lack of dense seismicity at depths $18-20 \mathrm{~km}$. This is the place where we suspect the decollement boundary to be.

\section{CHELUNGPU FAULT AND OTHER RELATED FAULTS}

The second significant characteristic of the Chi-Chi earthquake is that it triggered an active fault, the Chelungpu fault. From the crescent shape of the aftershock distributions (Fig. 4), we found that the main shock was not located precisely within any existing seismic zone or even in the Sun-Moon Lake seismic gap. Instead, it shifted to the west of the Sun-Moon-Lake seismic gap, near the town of Chi-Chi. The reason that the main shock left the Sun-Moon Lake seismic gap and deviated to the west was quite probably due to the participation of the Chelungpu 
fault. This fault forms a weak belt that acted as a 'loose' medium to trigger the earthquake even before it became 'mature'. If we add the radiated energy of the major aftershocks $(M>5.0)$ within the first four hours to the main shock, the magnitude of the main shock of 7.3 would be increased to 7.5. This means that the main shock of the Chi-Chi earthquake should have been larger, if there had not been a weak fault nearby to ignite the main shock. This weak zone, the Chelungpu fault, must have very few and very weak 'asperities', which made it easy to break. It is not surprising to find that the aftershocks had almost nothing to do with the Chelungpu fault (Fig. 4), which seemed to completely 'relax' after its breakdown during the main shock. The Chelungpu fault acted approximately like a kind of 'decollement' surface.

Figure 7 shows the line-drawing of a seismic profile provided by the Chinese Petroleum Company (CPC), describing the possible underground structure of the Chelungpu fault. This is a relatively good quality profile cutting across the hill area between the Chelungpu fault and the Shuantung fault, a few kilometers north of the Choshuihsi stream (Fig. 2a). Below the surface, the Chelungpu fault seems to follow a sedimentary layer, the Chinshui Shale, penetrating to a depth of $5 \mathrm{~km}$ in a curved shape. This layer-coupled fault dips 30 degrees to the east and strikes north-south, which agrees well with the focal mechanism of the main shock. On the surface, we see that the Chelungpu fault keeps track with the outcrops of the Chinshui

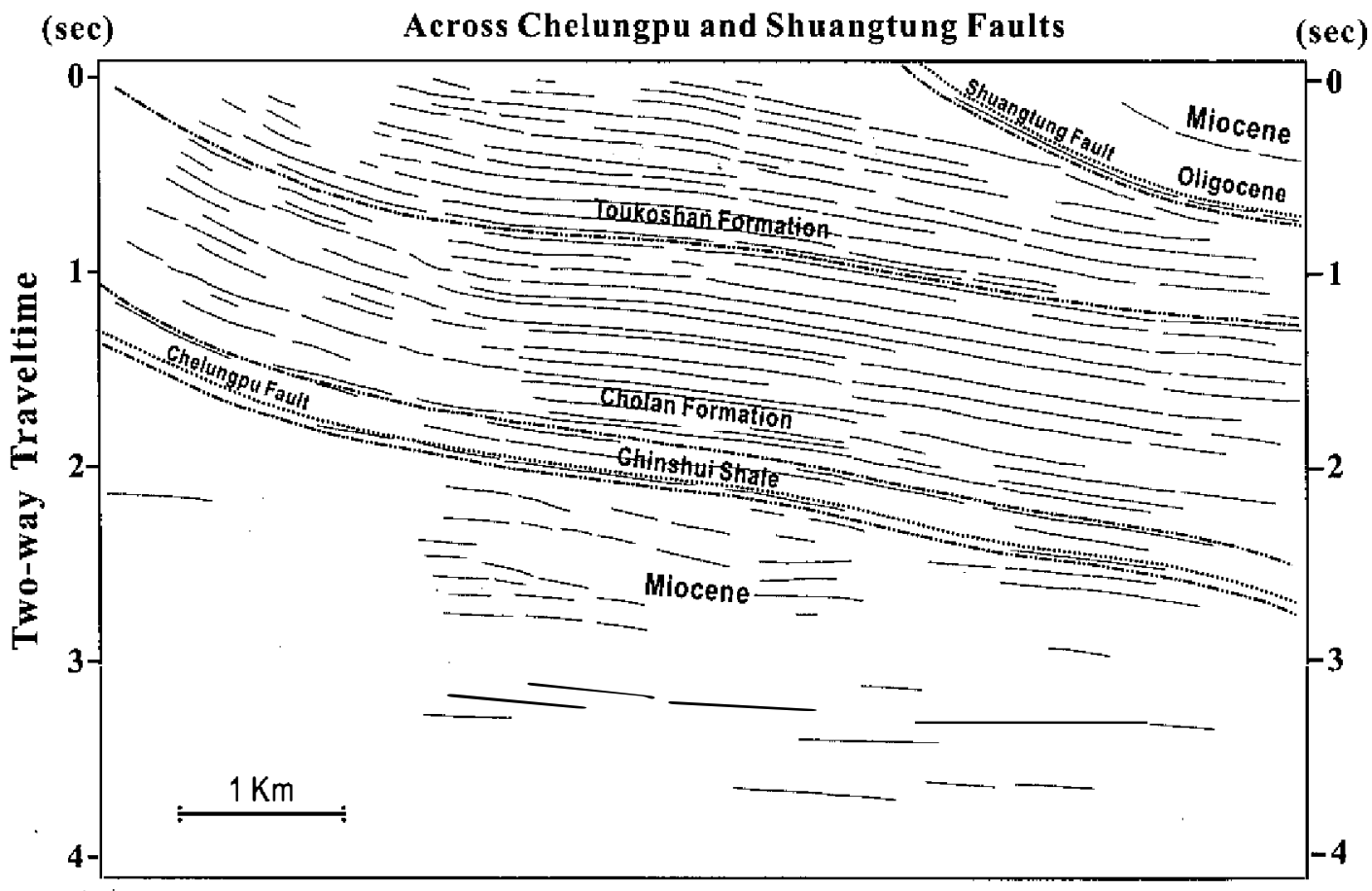

Fig. 7. Sketch of a seismic reflection profile between the Chelungpu and Shuantung faults obtained by the CPC. The layers are relatively flat with little tilting and folding, but as they approach the surface, they quickly bend upward. It is suggested the fault waces follow the layer's bedding. 
Shale, especially where it follows this shale layer as it enters the hill areas north of Takang and west of Shuanchi (Fig. 2a).

The Chinshui Shale belongs to the Pliocene age (600-800 Ma). This layer is not thick (100-400 m), but it is distributed over a very wide area, covering most of westem Taiwan. This shale layer represents a quiet period of deposition between the Miocene sedimentation which is due to the west with sources from the mainland China and the fast Pliocene-Pleistocene sedimentation due to the east with sources from the Central Mountain of Taiwan. This is a significant boundary with different sediments from different sources, and it is not unreasonable to suggest that it had become a controlling layer for tectonic movements. Recent electromagnetic data showed low electric resistivities along the Chelungpu fault (CS Chen, personal communication), which could be a result of intrusion liquid along cracks in the shale. This would provide an opportunity for this shale layer to become lubricated enough to move under the tectonic pressure.

There is another fault, the Shuantung fault, lies to the east of the Chelungpu fault, which also dips to the east but at a larger angle of about 45 degrees (Figs. 2a and 7). The Shuantung fault separates the Pleistocene Toukoshan formation (west, gravel) from the Miocene Kueichulin formation (east, massive sandstone). A deep well drilled near the Shuantung fault by the CPC (Tzukang well \#1) hit the underground fault at $2000 \mathrm{~m}$ depth. Above the fault there exists an Oligocene hard rock layer, the Paileng formation (massive quartz sandstone), while below the fault lies the Pleistocene Toukoshan formation. In fact, the Toukoshan Iayer spreads widely over most of the surface area between the Chelungpu and the Shuantung faults, and all of those west of the Chelungpu fault. Its thickness beneath the Taichung basin is at least $3 \mathrm{~km}$ (ref. Fig. 11). This layer is full of gravels and conglomerates eroded from the Central Range which was raised forming a high mountain in the Penglai orogeny. The layer is thicker on the eastern side and locally forming bad land scenery where it is exposed at the surface.

Figure 8 shows surface displacements caused by the earthquake based on the GPS data. We can see that large displacements occurred to the east of the Chelungpu fault, but to the west displacements were much smaller. It seems that only the block east of the fault was in action, while the western block remained still. Field examinations had shown that the Shuantung fault might not have moved during the Chi-Chi earthquake, however, the block between these two major faults could have tilted. Due to the weakness of the fault-related Chinshui Shale layer, it is possible that the western side of the block near the Chelungpu fault would 'slide' largely upward, but along the eastern side near the Shuantung fault the acting force was absorbed by the gravel layer. Some contraction of the gravel layers has been observed near Shihkang, which may express distortions of this kind of rock, accommodating the tilting movement.

The excitation of the weak Chelungpu fault largely reduced the stress drop during the occurrence of the main earthquake. One obvious consequence is the low frequencies radiated from the source. From the strong motion data (Fig. 9), we find that the Peak Ground Acceleration (PGA) level of the Chi-Chi earthquake is only 0.5 times that observed in other places of the world for the earthquake with the same magnitude (Tsai et al. 1999). On the other hand, the Peak Ground Velocity (PGV) values are 1.8 times higher. The PGV normally represents a lower frequency property than the PGA. This means that the Chi-Chi earthquake is of a 'lowforce' and 'high-momentum' type. The corner frequency of the far-field seismic data was also 
(a)

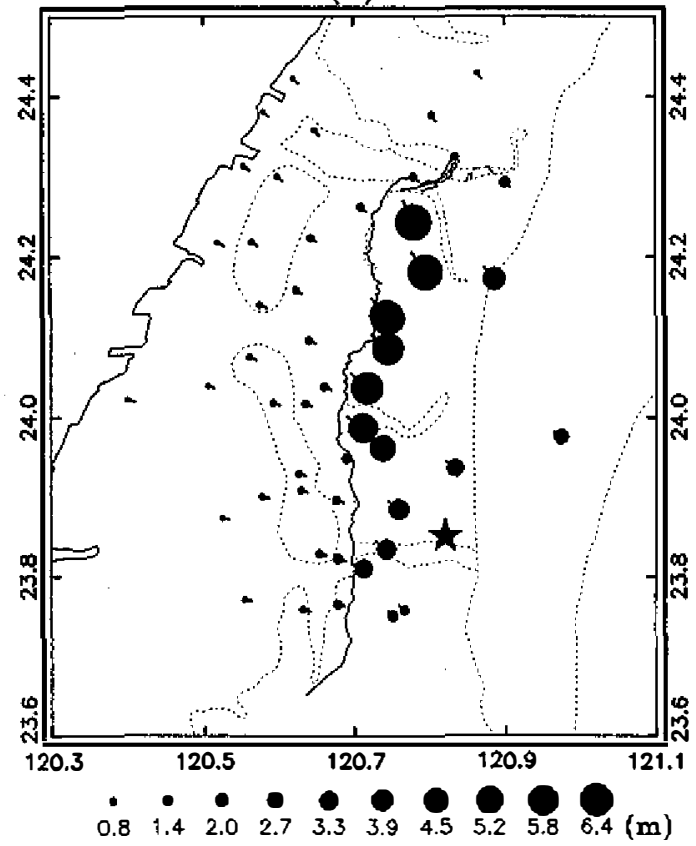

(b)

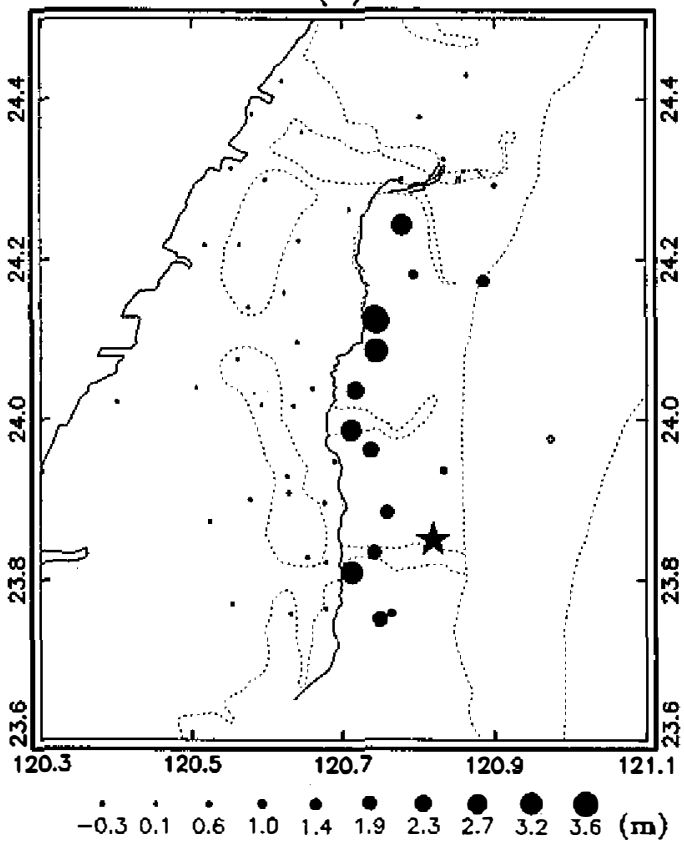

Fig. 8. (a) Surface horizontal displacements (small tic indicating the displacement direction) and (b) surface vertical displacements measured after the Chi-Chi earthquake using GPS data (data were collected by the Institute of Earth Sciences, Academic Sinica and the Central Geological Survey). It seems that the Chelungpu fault acted as a boundary separating the weak and strong shaking zones. The distinction of ground motions across the fault is tremendously large.

quite low, only about $0.1 \mathrm{~Hz}$. This kind of seismic data strongly indicates a low friction, weak source fault for the Chi-Chi earthquake. The 'frail' movement on the fault surface is not capable to transmit 'strong' enough high frequency seismic waves which may have largely lessened the shaking damage. This large, but weak, source property is just similar to those described before. A thin-skinned model can explain these nicely.

\section{TACHIAHSI-TAANHSI TRANSVERSE STRUCTURAL BAND}

The third special characteristic of the Chi-Chi earthquake is the right-tum of the Chelungpu fault at its northern tip (Fig. 2a), and the large displacement on the surface as well as underground occurred near this region. The fault trace slanted ENE crossing the Tachiahsi and Taanhsi streams until it was stopped by the Shuantung fault at the far-northeastern end. We can see in Fig. 8 that large horizontal and vertical surface displacements were measured to the east 

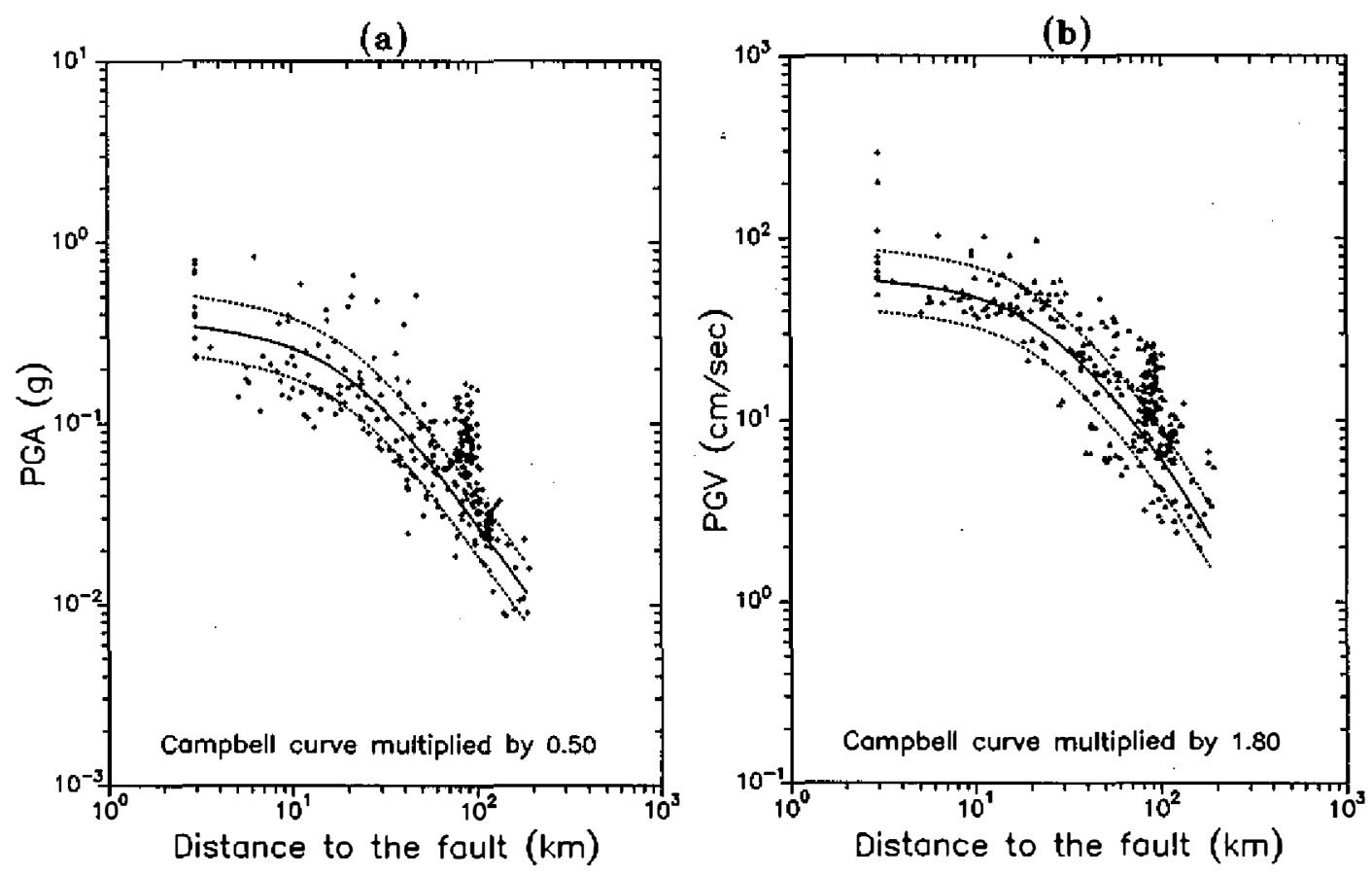

Fig. 9. (a) PGA and (b) PGV distance attenuation distributions compared to the 1997 Campbell's attenuation law (Campbell 1997). A low PGA by 0.5 and a high PGV by 1.8 are observed, compared to world standards. The Chi-Chi earthquake happened to be a low 'PGA' and high 'PGV' earthquake which was seldom observed in other places of the world.

of the fault. More interestingly, these displacements also show larger values toward the north, especially under the Shihkang and Tungshih areas which are located along the bank of the Tachiahsi stream, $50 \mathrm{~km}$ north of the epicenter. Actually at one site near Shibkang, the Tachiahsi stream was cut by an $8 \mathrm{~m}$ displacement that formed a new waterfall. Near this place, one surface rupture measurement was reported to be as high as $9.8 \mathrm{~m}$ horizontally and $5.2 \mathrm{~m}$ vertically ( $\mathrm{Ma}$ et al. 1999). These surface rupture numbers due to a single earthquake are rare even in world records. It is also interesting to find that the sense of the fault displacement is still dominated by the reverse movement, although the fault direction has changed. The slippage on the fault surface seems to be incapable of standing much lateral movement, a hint of the property of the 'decollement'. Except for GPS results, the source fault-slippages extracted from local or tel-seismic data (Ma et al. 1999) also show large underground distortions aggregated at the northern end. Slip values of 7 to $10 \mathrm{~m}$ were estimated under the towns of Shihkang and Tungshih where severe construction damage occurred. It is also significant to point out that the bending of the fault's direction by 70 degrees to the east seems to distinguish the ChiChi earthquake even more clearly from the 1935 earthquake sequence (Fig. 3b).

Early in the sixties, Meng (1965) proposed that a Tachaichi-Taanhsi transverse structural 
band, rending in the east-west direction, may exist under the Tachiahsi and Ta-anhsi streams. This structural band separates the northern Miaoli system (with gas or oil deposits) from the southern Taichung system (with no indications of gas or oil). From the geomorphic map (Fig. $2 b$ ), it is easy to see an ENE oriented topographic highland standing between the two main river systems. Similarly in Fig. 2a, we can see that the northern part of the Shuantung fault bends due to an eastward expansion of structures. Moreover from the TPL seismicity distribution (Fig. 3b), we find a small branch extending from the 1935 earthquake and heading to the east with increasing depths (ref. Wang and Shin 1998 for details). This branch goes under the

\section{Bouguer Gravity Anomaly}

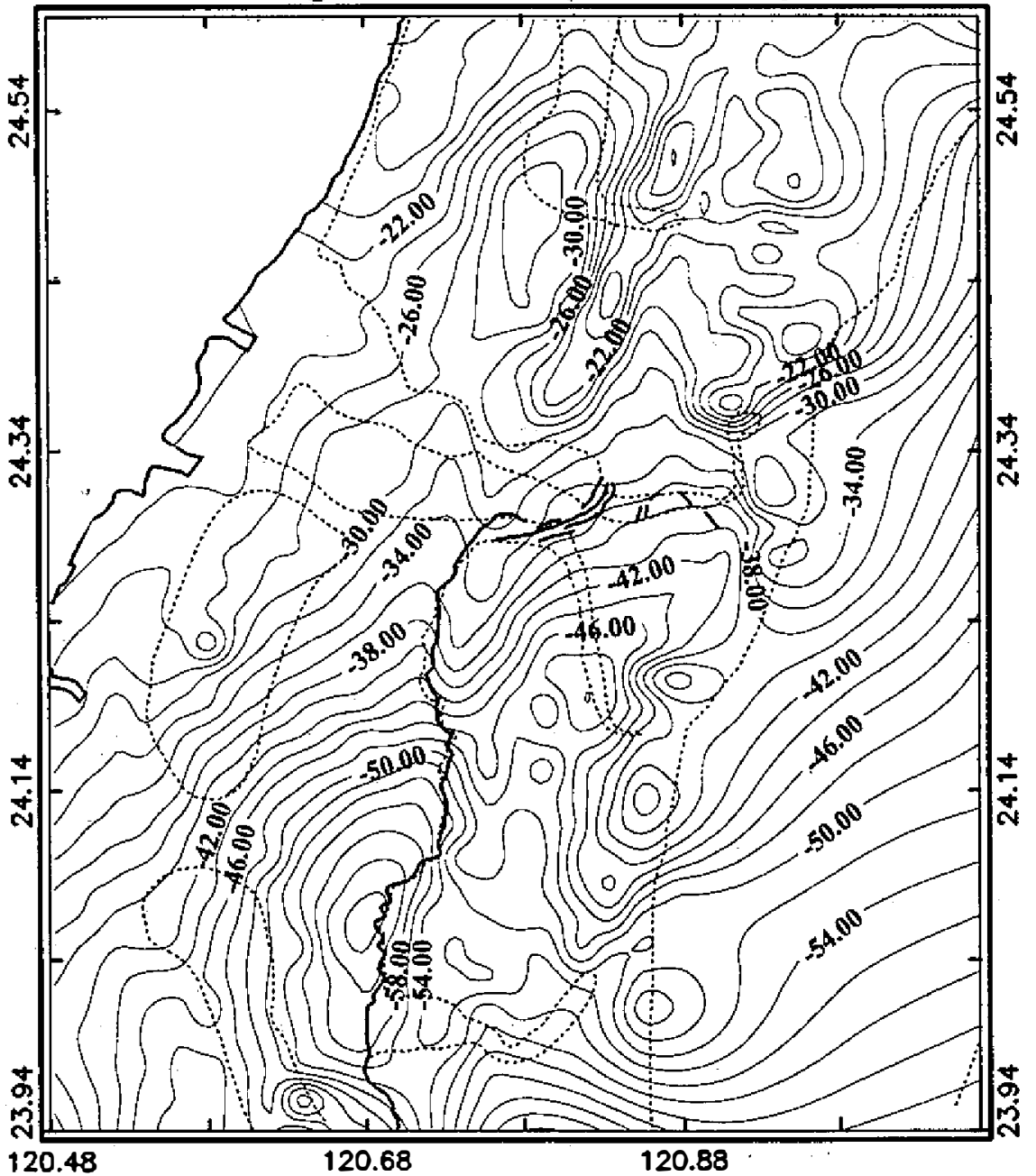

Fig. 10. Bouguer gravity anomaly in central Taiwan. A northeast trend of gravity contours indicates a bend in the underground structure to the east at the northern part of the Chelungpu fault. 
Tachiahsi and Ta-anhsi streams. Finally, the Bouguer gravity anomaly map, shown in Fig. 10 (Yen et al. 1996), reveals a very clear northeastern distribution of the underground mass across the Taichung basin and the Tachiahsi-Taanhsi river areas. All of the above evidences strongly support the existence of a Tachiahsi-Taanhsi transverse structural band sitting approximately in the east-west direction.

The east-west oriented transverse band would be quite useful in explaining the behavior of the Chi-Chi earthquake in the regions near the Tachiahsi and Ta-anhsi streams. When the earthquake initiated, the rupture front moved northward until it met the transverse structure, which stopped any further rupture expansion, leading the force to accumulate quickly under the Shihkang and Tungshih areas and causing enormous displacements both underground and on the surface. This blocking effect would also hinder further northward extension of the Chelungpu fault which takes a turn to the east there. The transverse structure could be a zone rather than a limited line; hence, the surface fault traces spread into several segments in this region. In some places the ground would not break but be uplifted to as high as $9 \mathrm{~m}$ like that occurred at the Shihkang dam. The blocking effect is quite obvious in such of 'squeezing' places.

The rise of the Tachiahsi-Taanhsi transverse structural band may be related to the ascendance of the Chinshui Shale layer in this region before it is exposed at the surface in the north (Fig. 2a). Basically, all of the above may have been due to an uneven configuration of the deep PKH basement surface (or uneven Moho surface (Rau and Wu 1995)). The modification of basement surface may have occurred between two different thin-skinned thrust-fold systems in the Miaoli and the Taichung areas which join to alter the shallow structure's development in the middle part of the Tachiahsi and Ta-anhsi streams.

\section{SUMMARY OF CHI-CHI EARTHQUAKE CHARACTERISTICS}

To accumulate evidences in favor of the thin-skinned thrust model, we list the observed facts about the Chi-Chi earthquake as follows:

\section{1. Main shock :}

1) The source focal mechanism was a pure reverse type dipping 30 degrees to the east, striking $\mathrm{N} 20 \mathrm{E}$, at a depth of $8 \mathrm{~km}$. The orientation of the main shock agrees well with the orientation of the southern part of the Chelungpu fault.

2) The source rupture covers an area of $40 \mathrm{~km} \times 100 \mathrm{~km}$ with a maximum slip of $10 \mathrm{~m}$ occurring at $50 \mathrm{~km}$ north of the source at a depth of $10 \mathrm{~km}$. This position is under the towns of Shihkang and Tungshih, where the largest damage occurred.

3) The frequency content of the radiated waves was relatively low with PGA values 0.5 times lower, and PGV values 1.8 times higher than the world standards. The source spectrum was dominated by low frequencies with the corner frequency around $0.1 \mathrm{~Hz}$. This is a low-force and high-momentum type of source.

4) The main shock was located neither inside any previous seismically active region, nor in the 
Sun-MoonLake seismic gap, but shifted to the west and connecting with the active Chelungpu fault.

\section{2. Aftershocks:}

1) The aftershocks within the first 4 hours were situated mostly in the Sun-Moon Lake seismic gap and presented the same focal mechanism as that of the main shock.

2) The aftershocks within 4 months after the main shock were distributed over a wide area of $120 \mathrm{~km}$ square surrounding the Peikang basement high.

3) The aftershocks did not seem to correlate with the Chelungpu fault which was triggered by the main shock.

4) The depth distribution of most of the aftershocks was concentrated in the upper $10 \mathrm{~km}$, with a zone lack of apparent seismicity at depths of 18 to $20 \mathrm{~km}$.

\section{3. Induced Faults:}

1) The earthquake triggered an existing active fault, the Chelungpu fault, with a total length of $90 \mathrm{~km}$. The southern $70 \mathrm{~km}$ trended in the south-north direction with pure reverse thrusting at a low dip angle of 20-30 degrees, while the northern $20 \mathrm{~km}$ made a 70-degree turn toward the east but was also dominated by the reverse displacement on the fault surface.

2) The hanging wall side to the east of the fault had much larger displacements and suffered from more damage than the foot wall side to the west. The foot wall seemed less affected by the earthquake, while the hanging wall was largely tilted and distorted.

3) Underground, the Chelungpu fault followed a weak layer, the Chinshui Shale. This weak layer has a low electric resistivity and is suspected to be a less resistive boundary which may slide easily.

4) The Shuantung fault, $10 \mathrm{~km}$ to the east of the Chelungpu fault, was not involved in the fault movement during the source faulting. A thick gravel layer below it may have absorbed the land deformation. Some gravel contractions have been observed on the surface.

\section{4. Ground Deformations:}

1) Ground deformation data have been produced from: a) GSP measurements, b) strong motion accelerations integrated to displacements, c) fault surface rupture assessments, d) landslide observations from aircraft or satellites, and e) underground water table variations from hydrologic monitoring wells.

2) All the observations definitely indicate different responses of ground motion on the hanging wall side and on the foot wall side. More apparent dislocations happened on the hanging wall side, which moved to the west then to the northwest, as going from the southern to the northern part. The foot wall side seemed to remain still during the fault slippage.

3) A nucleation of displacements was found near the northern end of the Chelungpu fault just under the Tachiahsi stream. Surface as well as subsurface data all show accumulation of stresses in this area. 
4) Most collapsed constructions occurred along the fault race, especially on the eastern, hanging wall side. The damage from shaking was relatively low. The intensity map shows a bias of intensity contours toward the east of the fault with an area ratio of about 1:6 on the two sides.

\section{A THIN-SKINNED THRUST MODEL}

The thin-skinned thrust model can be employed to explain all the observations of the ChiChi earthquake described above. This model has long been applied to describe imbricated structures in the fault-and-fold belt of the western Taiwan foothills (Suppe and Jamson 1979). Geophysical as well as borehole data have revealed that the basement is little, if any, affected by the large scale faulting and folding in cover rocks. Similar examples may be found in the southern Appalachians of North America and the Canadian Rockies (Davis et al. 1983; Cook 1994). Figure 11 provides a possible subsurface structure model responsible for the Chi-Chi earthquake, based on Suppe's thin-skinned thrust idea, seismic profiles and borehole data from the CPC. A decollement surface at depths of 10 to $20 \mathrm{~km}$ is proposed corresponding to a zone lack of dense seismicity. This surface has a slope of about 8 degrees, which matches the uplift of the PKH, forming a wedge type of overthrusting as described by Dahlen et al. (1984). This detachment boundary may have been formed by the lithologic contrast of a weak layer with rocks such as shale or calcite (Chen 1978; Covey 1984). Different slopes may occur along the decollement boundary where harder rocks are encountered and form 'ramps' with

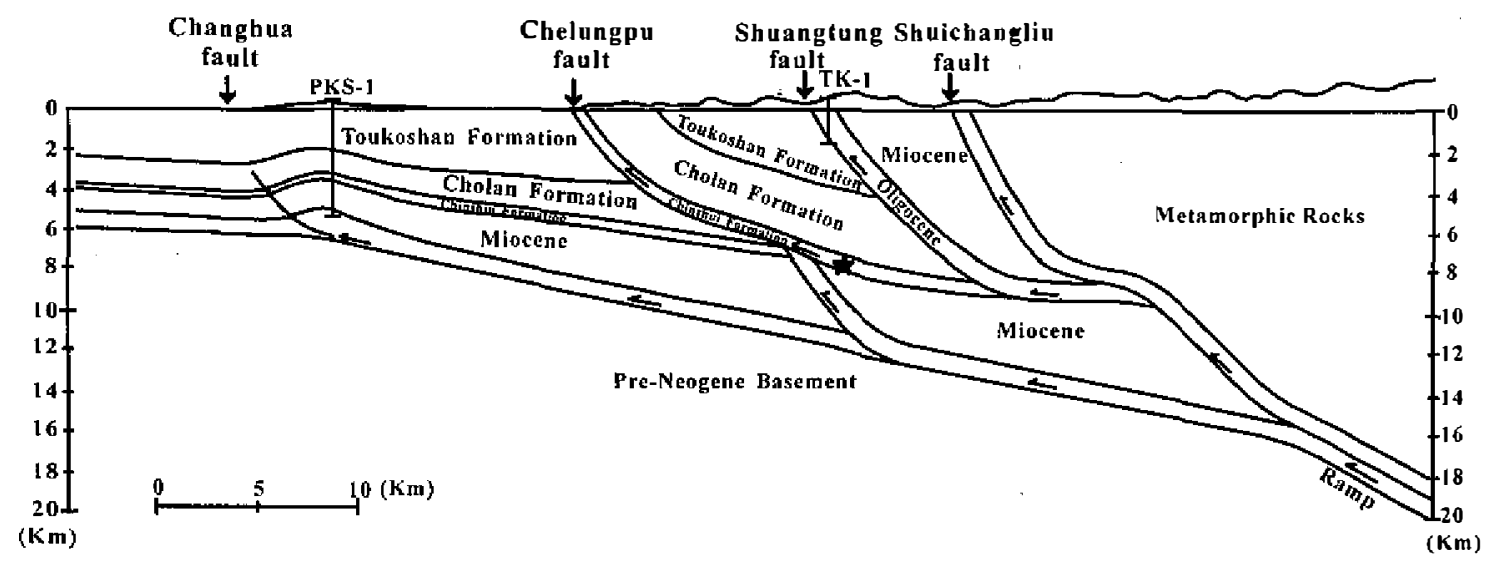

Fig. 11. Thin-skinned model modified from Suppe (1980b) after putting in certain reflection and borehole data (PKS-1 and TK-1) from the CPC. This figure appropriately describes the imbricated structure of the western Taiwan foothills. The Chi-Chi earthquake (star symbd) was situated at the place where a branch of the fault extended from the decollement but was ramp-bend folded, and then followed a weak layer of Chinshui Shale until exposed at the surface. 
higher resistance. The tectonic compression due to the arc-continent collision in eastern Taiwan provides the force pushing the shallow crust to move horizontally above the decollement. When the movement is hindered by the steep ramp of the $\mathrm{PKH}$, the stresses accumulate and induce the development of a thrust movement along another shallower weak boundary which may extend to the surface. This shallow weak layer, in the case of the Chi-Chi event, is the Chinshui Shale, which creates the Chelungpu fault along its bedding.

Based on the thin-skinned thrust model in Fig. 11, the behavior of the Chi-Chi earthquake can be explained nicely and sufficiently. The shallow weak layer-coupled fault, i.e., the Chelungpu fault, acted as a medium which was weak and lubricated enough to trigger the strain energy accumulated by the earthquake even before it was mature. The premature triggering of the earthquake frailly pushed large volumes of material sliding along the Chelungpu fault, and accordingly, exhibited a low-force and high-momentum type of movement. This low friction detachment motion, although causing large surface fractures, exhausted its stored strain energy thus not many aftershocks were produced on the fault surface afterward. The aftershocks, instead, bloomed along the steep PKH ramp boundary, where large strains had already accumulated. The occurrence of aftershocks helped to release the rest of the energy.

The loose sliding along the Chelungpu fault made the block east of the fault tilt largely with the western block remaining almost untouched. This explains the obvious distinctions in surface displacements and construction damages across the fault. Furthermore, at the northern end, an east-west trending Tachiahsi-Taanhsi transverse structural band arose that accounted for the large, abnormal ground distortions found there. The obstruction of the transverse barrier may have blocked the further northward growth of the source rupture, which piled up the breaking forces and caused greater ground deformation. The rise of such a ransverse structure may have been caused by shape alternations of the PKH surface which would have reset the distribution of cover layers to form a connection between the northern Miaoli and the southern Taichung systems.

To sum up, the thin-skinned thrust model seems quite appropriate to interpret the Chi-Chi earthquake. However, the detailed structure of this model still requires more data to elaborate it. A deep seismic reflection survey is definitely needed to provide constrains on the subsurface structures. Deep wells, although being costly, are also worthwhile because of the reachable depths concerned. In light of the thin-skinned model, plenty of studies should be scheduled or conducted for the Chi-Chi earthquake, this extraordinary century event.

Acknowledgments This research was sponsored by the National Science Council under grant NSC89-21 16-M-008-002 and by the Central Weather Bureau under grant CWB88-2E01 . We are grateful to the CWB for generously providing us with the aftershock data. Some seismic reflection profiles and maps have come from the Chinese Petroleum Corporation and are highly appreciated. We are also grateful to Dr. C. S. Liu and Dr. T. C. Shin for their valuable review and suggestions.

\section{REFERENCES}

Biq, C., 1972: Western Taiwan thrusts, active or inactive? Acta Geol. Taiwan, 15, 63-75. 
Barrier, E., 1986: The double collision of Taiwan: an active orogeny. Tectonophysics, $\mathbf{1 2 5}$, 39-72.

Bonilla, M. G., 1977: Summary of Quaternary faulting and elevation changes in Taiwan. Mem. Geol. Soc. China, 2, 43-55.

Campbell, K. W., 1997: Empirical near-source attenuation relationships for horizontal and vertical components of peak ground acceleration, peak ground velocity, and pseudoabsolute acceleration response spectra. Seism. Res. Let., 68, 154-179.

Chang, C. H., Y. M. Wu, T. C. Shin, and C. Y. Wang: Relocation of the 1999 Chi-Chi earthquake in Taiwan. TAO, 11, 581-590.

Chen, J. S., 1978: A comparative study of the refraction and reflection seismic data obtained on the Changhua plain to the Peikang shelf, Taiwan. Petro. Geol. Taiwan, 15, 199-217.

Cook, F. A. and J. L., Varsek, 1994: Orogen-scale decollements. Rev. of Geophys., 32, 37-60.

Covey, M., 1984: Lithofacies analysis and basin reconstruction, Plio-Pleistocene westem Taiwan foredeep. Petro. Geol. Taiwan, 20, 53-83.

Dahlen, F. A., J. Suppe, and D. M. Davis, 1984: Mechanics of fold-and-thrust belts and accretionary wedges: cohesive Coulomb theory. J. Geophys. Res., 89, 10087-10101.

Davis, D. M., J. Suppe, and F. A. Dahlen, 1983: Mechanics and fold-and-thrust belts and accretionary wedges. J. Geophys. Res., 88, 1153-1172.

Davis, G. H., and S. J. Reynolds, 1996: Structural Geology of Rocks and Regions. John Wiley and Sons, Inc., New York, USA, 319-339.

Elishewitz, B., 1963: A new interpretation of the structure of the Miaoli area in the light of the decollement tectonics of northern Taiwan. Petro. Geol. Taiwan, 2, 21-45.

Ho, C. S., 1986: A synthesis of the geologic evolution of Taiwan. Tectonophysics, 125, 1-16.

Hsu, S. K. and J. C. Sibuet, 1995: Is Taiwan the result of arc-continent or arc-arc collision? Earth Planet Sci. Lett., 136, 315-324.

Hu, J. C., J. Angelier, and S. B. Yu, 1997: An interpretation of the active deformation of southern Taiwan based on numerical simulation and GPS studies. Tectonophysics, 274, 145-169.

Liu, C. S., I. L., Huang, and L. S. Teng, 1997: Structural features off southwestern Taiwan. Mar. Geol., 137, 305-319.

Lu, C. Y., and K. J. Hsu, 1992: Tectonic evolution of the Taiwan mountain belt. Petro. Geol. Taiwan, 27, 21-46.

Ma, K. F., C. T. Lee, and Y. B. Tsai, 1999: The Chi-Chi, Taiwan earthquake: large surface displacements on an inland thrust fault. EOS, 80, 605.

Meng, C. Y., 1965: Lateral movement in the northern half of western Taiwan. Petro. Geol. Taiwan, 4, 89-92.

Rau, R. J., and F. T. Wu: Tomographic imaging of lithospheric structures under Taiwan, Earth Planet. Sci. Lett., 135, 517-532..

Seno, T., 1977: The instaneous rotation vector of the Philippine Sea Plate relative to the Eurasian Plate. Tectonophysics, 42, 209-226.

Shin, T. C., 2000: Some Seismological Aspects of the 1999 Chi-Chi Earthquake in Taiwan, $T A O, 11,555-566$. 
Sun, S. C., 1985: The Cenozoic tectonic evolution of offshore Taiwan. Energy, 10, 421-432. Suppe, J., and J. Jamson, 1979: Fault-bend origin of frontal folds of the western Taiwan foldand-thrust belt. Petro. Geol. Taiwan, 16, 1-18.

Suppe, J, 1980a: A retrodeformable cross section of northern Taiwan. Proc. Geol. Soc. China, 23, 46-55.

Suppe, J., 1980b: Imbricated structure of westem foothills belt, south-central Taiwan. Petro. Geol. Taiwan, 17, 1-16.

Suppe, J., 1984: Kinematics of arc-continent collision, flipping of subduction, and back-arc spreading near Taiwan. Mem. Geol. Soc. China, 6, 21-34.

Teng, L. S., 1990: Geotectonic evolution of late Cenozoic arc-continent collision in Taiwan. Tectonophysics, 183, 57-76.

Teng, L. S., 1992: Geotectonic evolution of Tertiary continental margin basins of Taiwan. Petro. Geol. Taiwan, 27, 1-20.

Tsai, Y. B., and M. W. Huang, 1999: Strong ground motion characteristics of the Chi-Chi, Taiwan earthquake of September 21, 1999. Report to NSC.

Wang, C. Y., and T. C. Shin, 1998: Illustrating 100 years of Taiwan seismicity. TAO, 9, 589614.

Wu, F. T., R. J. Rau, and D. Salzberg, 1997: Taiwan orogeny: thin-skinned or lithospheric collision? Tectonophys., 274, 191-220.

Wu, F. T., and R. J. Rau, 1998: Seismotectonics and identification of potential seismic source zones in Taiwan. TAO, 9, 739-754.

Yeh, Y. H., R. C. Shih, C. H. Lin, C. C. Liu, H. Y. Yen, B. S. Huang, C. S. Liu, P. Z. Chen, C. S. Huang, C. J. Wu, and F. T. Wu, 1998: Onshore/offshore wide-angle deep seismic profiling in Taiwan. TAO, 9, 301-316.

Yen, H. Y., Y. H. Yeh, C. H. Lin, K. J. Chen, and Y. B. Tsai, 1996: Gravity survey of Taiwan. J. Phys. Earth, 43, 685-696. 